\title{
Article \\ Complex Maturity Method for Estimating the Concrete Strength Based on Curing Temperature, Ambient Temperature and Relative Humidity
}

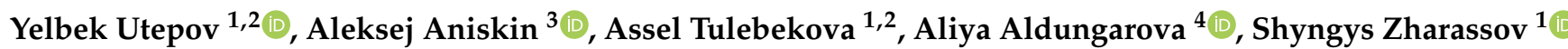 \\ and Assel Sarsembayeva ${ }^{1, * \mathbb{D}}$ \\ 1 Department of Structural Engineering, L.N. Gumilyov Eurasian National University, \\ Nur-Sultan 010008, Kazakhstan; utepov-elbek@mail.ru (Y.U.); krasavka5@mail.ru (A.T.); \\ zhshzh95@gmail.com (S.Z.) \\ 2 R\&D Department, CSI Research\&Lab (LLP), Nur-Sultan 010000, Kazakhstan \\ 3 Department of Civil Engineering, University North, 42000 Varaždin, Croatia; aaniskin@unin.hr \\ 4 Department of Architecture and Design, Toraighyrov University, Pavlodar 140000, Kazakhstan; \\ liya_1479@mail.ru \\ * Correspondence: assel_enu@mail.ru
}

\section{check for}

updates

Citation: Utepov, Y.; Aniskin, A.; Tulebekova, A.; Aldungarova, A.; Zharassov, S.; Sarsembayeva, A. Complex Maturity Method for Estimating the Concrete Strength Based on Curing Temperature, Ambient Temperature and Relative Humidity. Appl. Sci. 2021, 11, 7712. https://doi.org/10.3390/app11167712

Academic Editors: Doo-Yeol Yoo and Dario De Domenico

Received: 1 July 2021

Accepted: 19 August 2021

Published: 21 August 2021

Publisher's Note: MDPI stays neutra with regard to jurisdictional claims in published maps and institutional affiliations.

Copyright: (c) 2021 by the authors. Licensee MDPI, Basel, Switzerland. This article is an open access article distributed under the terms and conditions of the Creative Commons Attribution (CC BY) license (https:// creativecommons.org/licenses/by/ $4.0 /)$.

\begin{abstract}
The maturity method is deservedly considered one of the reliable indirect methods for determining the strength at the early stages of concrete curing. The main parameter in the calculation is the internal temperature of concrete that accumulates during the chemical reaction of concrete curing, while external factors such as ambient temperature and relative humidity are fallaciously omitted. In this work, the complex maturity method was developed based on ASTM C1074, accounting for the influence of ambient temperature and relative humidity and coefficients indicating their influence weight. The laboratory testing to measure the concrete strength by compression method and non-destructive sclerometer method were performed on concrete samples according to ASTM C109, GOST 22690, and GOST 10180. According to the calibration dependence of the existing and proposed methods results in comparison with the strength of cubic samples, the highest coefficient of determination $\mathrm{R}^{2}=0.976$ was revealed for the complex method of maturity, which indicates its reliability in contrast with sclerometer and traditional maturity methods. The determination of complex maturity allows for an evaluation of the current state of concrete strength, but also reduces the waiting time for concrete curing and increases the economic effect during construction.
\end{abstract}

Keywords: concrete strength; temperature-time factor; laboratory testing; compression strength; complex maturity

\section{Introduction}

Achieving sufficient concrete strength during the curing time is essential for the continuation of concrete and other construction work. Early estimation of concrete strength reduces downtime while waiting for strengthening. Temperature and humidity are the important factors affecting the curing time [1-4]. Early works on the maturity method used to estimate the strength of the concrete date from the mid-1950s, by [1,5], who determined the relationship between accumulation of datum temperature and the concrete strength gain. In the 1970s, the authors of [2] proposed continuous monitoring of the current calculation of maturity using a computer. According to [3], the maturity concept serves as an effective way of predicting the early-stage strength, while the authors of [6] stated that the standard cylinder strength underestimated the core strength by more than $40 \%$ when concrete curing occurred in cold weather, although the maturity method overestimated concrete strength by less than $10 \%$. Ref. [7] also proved maturity method's applicability for mass concrete with large aggregate grain diameters, low cement dosage, and low hydration 
temperatures, although [8] specified that the core compressive strength from the midsection was within $\pm 15 \%$ of the predicted values and core results from the bottom section were generally higher than the predicted values. Ref. [9] has reviewed and studied the rate of temperature increase during concrete curing in detail, but also predicted the strength gain over the curing and tested a wide range of test settings for ambient temperature and different concrete mixtures. Ref. [10] considered various curing conditions in the laboratory and on-site, where he evaluated the strength-maturity relationship by NurseSaul and Arrhenius maturity functions, and stated that the considered methods are only accurate for the first 7 days of concrete curing. Refs. [11,12] carried out the experimental and modelling study on the influence of curing temperature $(\mathrm{T})$ and relative humidity $(\mathrm{RH})$ on the compressive strength gain of cement mortars and determined that both of the parameters affect the strengthening rate, especially at the curing period. Despite the fact that numerous attempts have been made to account for the influence of external parameters such as ambient temperature and humidity, there is no unified method for calculating the complex maturity to date, which would most accurately convey the state of concrete strength during the curing. Thus, it turns out that ambient relative humidity and ambient temperature significantly affect the maturity and strength relationship of concrete; however, this process was overlooked in [13,14], and in other sources [15-19]. The main parameter in the calculations is the internal temperature of the concrete that accumulates during the chemical reaction of concrete maturation, while external factors such as ambient temperature and relative humidity were wrongly ignored.

The purpose of this study is to develop a detailed methodology to calculate the complex maturity, accounting for the external and internal parameters such as internal and ambient temperature and ambient relative humidity, which would weigh the influence ratio of each parameter and most accurately convey the relationship of gained strength with the maturity of concrete over curing time. A complex maturity method was developed based on ASTM C1074, accounting for the influence of ambient temperature and relative humidity, as well as coefficients indicating their influence on weight.

\section{Materials and Methods}

The proposed method is based on [13], which evaluates the strength of the cementbased concrete by the Nurse-Saul maturity method. The above method was previously determined based only on the principle of temperature accumulation over time (see Equation (1)).

$$
M(t)=\sum\left(T_{a}-T_{0}\right) \Delta t
$$

where:

$M(t)$ - the temperature-time factor at age $t$, degree-days or degree-hours;

$\Delta t$ - a time interval, days or hours;

$T_{a}$-average concrete temperature during time interval $\Delta t,{ }^{\circ} \mathrm{C}$;

$T_{0}$-datum temperature, ${ }^{\circ} \mathrm{C}$.

The Nurse-Saul method for calculating the maturity of concrete has been improved by including the parameter of ambient humidity and ambient temperature in the basic formula of maturity. Here, the impact of internal humidity in a gaseous stage was not considered as, according to the system equilibrium theory, the inner pores always tend to be fully saturated. In addition, depending on changes in temperature and pressure, processes of evaporation or condensation occur so that the moisture remains fully saturated in closed pores [20]. Thereby, the maturity gains a complex sense and is referred to as complex maturity $M_{c}$, which includes 3 parameters: internal temperature (IT), ambient temperature (AT) and ambient relative humidity (ARH), which may be expressed by Equation (2).

$$
\begin{gathered}
M_{c}=\sum M_{i} \cdot \bar{\gamma}_{i}=M_{I T} \cdot \bar{\gamma}_{I T}+M_{A T} \cdot \bar{\gamma}_{A T}+M_{A R H} \cdot \bar{\gamma}_{A R H} \\
M_{I T}=M(t) ; \quad M_{A T}=\sum(A T \cdot \Delta t) ; \quad M_{A R H}=\sum(A R H \cdot \Delta t) ;
\end{gathered}
$$


where: $i$-parameters affecting the concrete strength gain, such as IT, AT, and ARH; $M_{i}-$ maturity of $i$ parameter, such as IT, AT, and ARH, expressed by Equation (3).

$\bar{\gamma}_{i}$-average weight of $i$ parameter for 28 days of curing that is calculated by Equation (4) below.

$$
\bar{\gamma}_{i}=\frac{1}{28} \sum_{t=1}^{28} \gamma_{i, t}
$$

Regarding the aforementioned IT, AT, and ARH, Equation (4) may be extended in Equation (5):

$$
\bar{\gamma}_{I T}=\frac{1}{28} \sum_{t=1}^{28} \gamma_{I T, t} ; \quad \bar{\gamma}_{A T}=\frac{1}{28} \sum_{t=1}^{28} \gamma_{A T, t} ; \quad \bar{\gamma}_{A R H}=\frac{1}{28} \sum_{t=1}^{28} \gamma_{A R H, t} ;
$$

Here, the value of the weight of the $i$ parameter (namely IT, AT, and ARH) at the age of $t\left(\gamma_{i, t}\right)$ is calculated by Equation (6) below.

$$
\gamma_{i, t}=\frac{\left|r_{i, t}\right|}{\sum\left|r_{i, t}\right|}
$$

where: $r_{i, t}$-is a correlation coefficient between the $i$ parameter (IT, AT, and ARH) and the strength of the concrete at curing age of $t$ (from 1 to 28 days).

It should be noted that the sum of the weights is always equal to 1 (Equation (7)).

$$
\sum \gamma_{i, t}=\sum \bar{\gamma}_{i}=1
$$

By monitoring the internal and ambient temperature and relative humidity for 28 days every $0.5 \mathrm{~h}$ and obtaining the compressive strength (CS) for certain types of concrete mixture at each period of time (Table 1), it is possible to calculate the maturities corresponding to each parameter (Table 2) and to determine the trend line for the complex maturity-strength relationship.

To examine the proposed concept: a batch of cement-based concrete mixture of class B25 and grade M350 was retrieved from an operating concrete mixture manufacturing plant. The concrete mixture was used to prepare 17 vertical cylindrical samples with a diameter of $15 \mathrm{~cm}$ and a height of $15 \mathrm{~cm}$ [21], 15 cubes with an edge size of $10 \mathrm{~cm}$ [14] and 2 boxes $50 \times 50 \times 50 \mathrm{~cm}$ in size [22] at once, depicting the real structures on the site. All the samples and boxes were kept at the same temperature and humidity conditions. For compression testing on the 1st, 3rd, 7th, 14th and 28th days, 15 cylindrical and 15 cubic samples were prepared to be used in batches, three pieces at a time. The temperature sensors were inserted in the middle of the 2 cylindrical samples and 2 boxes and logged every $30 \mathrm{~min}$ for 28 days (Figure 1). Along with internal temperature, two more sensors were recording the ambient temperature and ambient relative humidity at the same time, by analogy with [23].

Table 1. Laboratory testing log template to retrieve the complex maturity-strength relationship.

\begin{tabular}{ccccc}
\hline Age, Hours & \multicolumn{3}{c}{$i$ Parameters } & \multicolumn{2}{c}{ Compressive Strength in Cylinders, MPa } \\
\hline $\mathbf{t}$ & IT & AT & ARH & CS \\
\hline 0.5 & 21.44 & 23.9 & 29.7 & 0 \\
\hline 1 & 21.56 & 23.4 & 30.6 & 0 \\
\hline 1.5 & 21.94 & 23.3 & 33.8 & 0 \\
\hline$\ldots$ & $\ldots$ & $\ldots$ & $\ldots$ & $\ldots$ \\
\hline 672 & 11.88 & 13.8 & 40.9 & 30.38 \\
\hline
\end{tabular}


Table 2. Calculation of complex maturity-strength relationship for laboratory cylinders.

\begin{tabular}{|c|c|c|c|c|c|c|c|c|c|c|c|}
\hline \multirow{2}{*}{$\begin{array}{r}\text { Age, } \\
\text { Days }\end{array}$} & \multicolumn{3}{|c|}{ Maturity of $i$ Parameter } & \multicolumn{3}{|c|}{$\begin{array}{l}\text { Correlation Coefficients } \\
\text { between } i \text { Parameters and } \\
\text { Compressive Strength }\end{array}$} & \multicolumn{3}{|c|}{$\begin{array}{l}\text { Weights of Maturity of } i \\
\text { Parameters }\end{array}$} & \multirow{2}{*}{$\begin{array}{c}\text { Complex } \\
\text { Maturity, } \\
{ }^{\circ} \text { C.Days }\end{array}$} & \multirow{2}{*}{$\begin{array}{c}\text { Compressive } \\
\text { Strength in } \\
\text { Cylinders, MPa }\end{array}$} \\
\hline & $\mathbf{M}_{\mathrm{IT}}$ & $\mathbf{M}_{\mathrm{AT}}$ & $\mathbf{M}_{\mathrm{ARH}}$ & $\left|\mathbf{r}_{I T}\right|$ & $\left|\mathbf{r}_{\mathrm{AT}}\right|$ & $\left|\mathbf{r}_{\mathrm{ARH}}\right|$ & $\gamma_{\mathrm{IT}}$ & $\gamma_{\mathrm{AT}}$ & $\gamma_{\mathrm{ARH}}$ & & \\
\hline 1 & 30.89 & 39.72 & 20.43 & 0.68 & 0.26 & 0.55 & 0.46 & 0.17 & 0.37 & 29.44 & 9.34 \\
\hline 2 & 55.38 & 107.37 & 36.76 & 0.92 & 0.84 & 0.88 & 0.35 & 0.32 & 0.33 & 61.59 & 13.71 \\
\hline 3 & 78.13 & 174.68 & 51.18 & 0.06 & 0.50 & 0.54 & 0.05 & 0.45 & 0.49 & 92.28 & 16.27 \\
\hline 4 & 99.38 & 245.08 & 64.25 & 0.38 & 0.04 & 0.20 & 0.61 & 0.07 & 0.32 & 122.63 & 18.09 \\
\hline 5 & 123.44 & 302.32 & 80.21 & 0.30 & 0.16 & 0.19 & 0.46 & 0.25 & 0.29 & 151.95 & 19.50 \\
\hline 6 & 150.46 & 345.37 & 98.36 & 0.58 & 0.33 & 0.52 & 0.41 & 0.23 & 0.36 & 179.81 & 20.65 \\
\hline 7 & 175.42 & 394.17 & 114.63 & 0.74 & 0.65 & 0.74 & 0.35 & 0.30 & 0.35 & 207.57 & 21.62 \\
\hline 8 & 199.75 & 444.27 & 130.40 & 0.47 & 0.15 & 0.35 & 0.49 & 0.16 & 0.36 & 235.21 & 22.47 \\
\hline 9 & 224.20 & 485.47 & 146.22 & 0.75 & 0.88 & 0.73 & 0.32 & 0.37 & 0.31 & 260.76 & 23.21 \\
\hline 10 & 245.46 & 530.46 & 158.87 & 0.76 & 0.33 & 0.79 & 0.41 & 0.18 & 0.42 & 284.81 & 23.88 \\
\hline 11 & 265.21 & 577.40 & 169.98 & 0.64 & 0.80 & 0.79 & 0.29 & 0.36 & 0.35 & 308.19 & 24.48 \\
\hline 12 & 284.53 & 629.17 & 180.77 & 0.69 & 0.38 & 0.59 & 0.41 & 0.23 & 0.36 & 332.44 & 25.03 \\
\hline 13 & 302.85 & 678.10 & 190.93 & 0.62 & 0.42 & 0.60 & 0.38 & 0.25 & 0.37 & 355.38 & 25.53 \\
\hline 14 & 320.96 & 724.01 & 200.85 & 0.54 & 0.32 & 0.45 & 0.41 & 0.24 & 0.34 & 377.42 & 26.00 \\
\hline 15 & 341.14 & 767.04 & 212.05 & 0.64 & 0.56 & 0.61 & 0.35 & 0.31 & 0.34 & 400.05 & 26.44 \\
\hline 16 & 360.26 & 818.35 & 222.76 & 0.49 & 0.43 & 0.51 & 0.34 & 0.30 & 0.36 & 424.09 & 26.84 \\
\hline 17 & 381.14 & 872.48 & 234.85 & 0.34 & 0.02 & 0.05 & 0.84 & 0.05 & 0.11 & 450.01 & 27.23 \\
\hline 18 & 403.44 & 922.70 & 248.34 & 0.39 & 0.14 & 0.21 & 0.53 & 0.19 & 0.28 & 476.06 & 27.59 \\
\hline 19 & 426.36 & 968.15 & 262.59 & 0.34 & 0.01 & 0.16 & 0.66 & 0.02 & 0.31 & 501.46 & 27.93 \\
\hline 20 & 448.45 & 1017.85 & 275.83 & 0.96 & 0.74 & 0.97 & 0.36 & 0.28 & 0.36 & 527.20 & 28.25 \\
\hline 21 & 461.33 & 1099.88 & 281.56 & 0.47 & 0.62 & 0.41 & 0.31 & 0.41 & 0.28 & 554.38 & 28.56 \\
\hline 22 & 477.11 & 1156.03 & 289.34 & 0.20 & 0.11 & 0.23 & 0.36 & 0.21 & 0.43 & 577.20 & 28.85 \\
\hline 23 & 495.61 & 1206.61 & 298.97 & 0.72 & 0.36 & 0.81 & 0.38 & 0.19 & 0.43 & 600.43 & 29.13 \\
\hline 24 & 511.93 & 1267.34 & 306.79 & 0.61 & 0.51 & 0.60 & 0.35 & 0.30 & 0.35 & 624.59 & 29.40 \\
\hline 25 & 527.83 & 1329.16 & 314.39 & 0.48 & 0.24 & 0.44 & 0.42 & 0.21 & 0.38 & 648.77 & 29.66 \\
\hline 26 & 544.70 & 1385.29 & 323.04 & 0.14 & 0.06 & 0.07 & 0.51 & 0.21 & 0.28 & 672.33 & 29.91 \\
\hline 27 & 562.47 & 1436.74 & 332.52 & 0.57 & 0.35 & 0.44 & 0.42 & 0.26 & 0.32 & 695.42 & 30.15 \\
\hline 28 & 580.97 & 1489.62 & 342.92 & 0.49 & 0.30 & 0.42 & 0.41 & 0.25 & 0.34 & 719.47 & 30.38 \\
\hline \multicolumn{7}{|c|}{ Mean value } & 0.42 & 0.24 & 0.34 & & \\
\hline
\end{tabular}

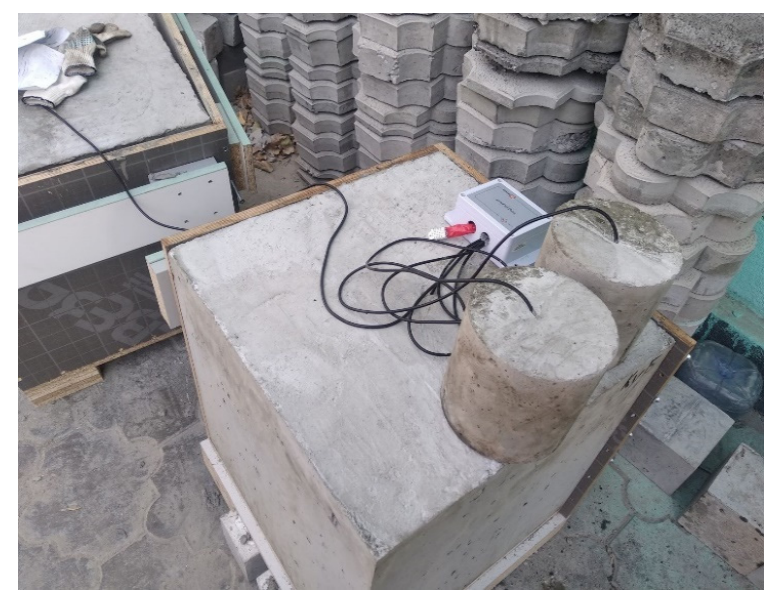

Figure 1. Testing set for estimating the concrete strength. 
Compression tests were conducted with a TMC-3224 hydraulic compression testing machine, according to [13] for cylindrical and [14] for cubic samples, in order to determine their average value of strength on the 1st, 3rd, 7th, 14th and 28th days (Figure 2). Intermediate values of the compressive strength of cylinders in Tables 1 and 2 are retrieved from the trend line equation from the strength-age relationship in Figure 3.
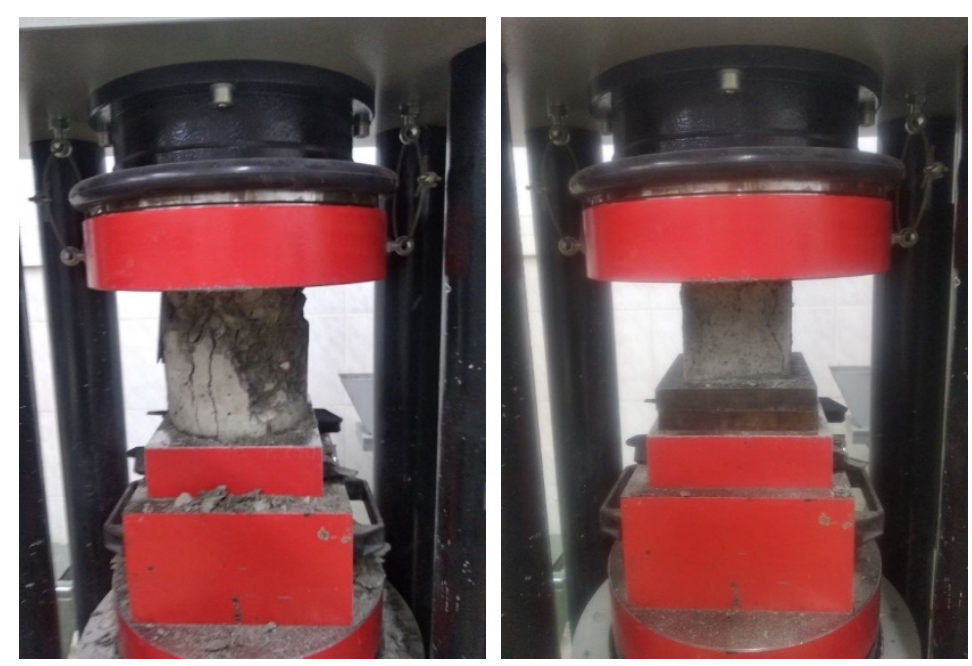

Figure 2. Compression test of cylindrical and cubic samples on the 1st, 3rd, 7th, 14th and 28th days.

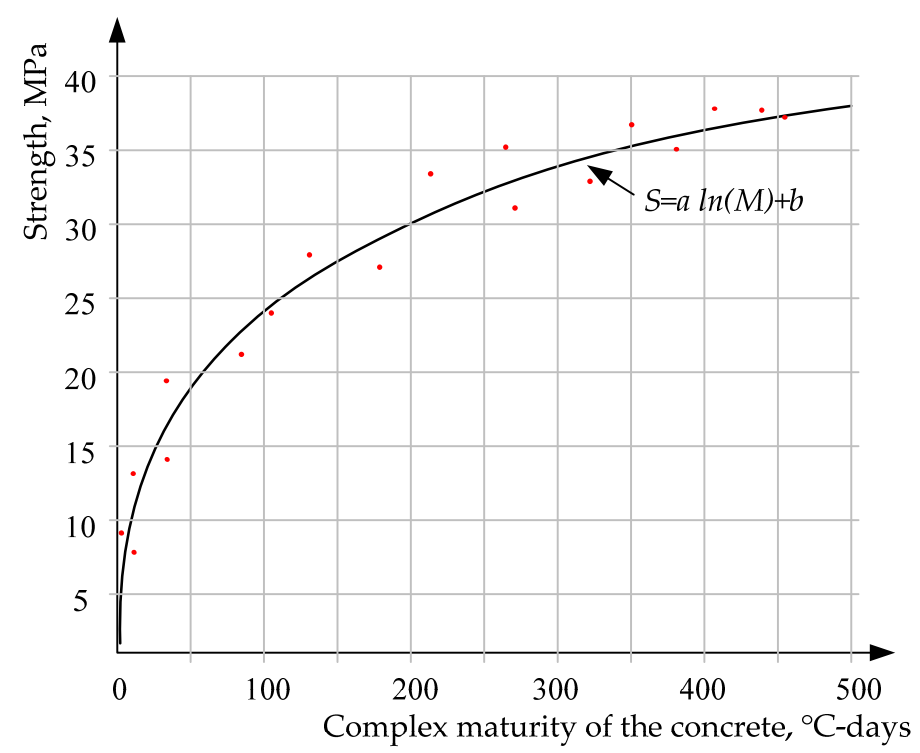

Figure 3. Relationship between complex maturity and strength of the concrete.

Correlation coefficients and weights for each of these parameters were calculated for every day in Table 2, and the mean value of the weight for the 28-day period is used in Equation (2). To determine the complex maturity-strength relationship, the trend line with the most fitting equation was drawn between the compressive strength of cylindrical samples and the complex maturity calculated by Equation (2). The resulting trend line corresponds to the logarithmic dependence $S=a \cdot \ln (M)+b$ in Figure 3, where $S$ is strength, and $M$ is the maturity of the concrete. The obtained complex maturity-strength relationship is used later to determine the current strength of the concrete by monitoring internal and ambient temperature and ambient relative humidity.

As mentioned above, the internal and ambient temperature and ambient relative humidity were also tracked for the 2 boxes (Table 3), representing the concrete structures curing on the site. The recorded data made it possible to calculate their complex maturity by 
Equations (2)-(7) at each time interval of testing (Table 4). According to the equation defined in Figure 3, corresponding to the trend line, it became possible to estimate the current strength of concrete in the boxes for each period by establishing the complex maturitystrength relationship for this particular type of concrete and to determine the stage of curing matching to $70 \%$ of the designed concrete strength, allowing for further construction.

Table 3. Field-testing log.

\begin{tabular}{cccc}
\hline Age, Hours & \multicolumn{3}{c}{$\boldsymbol{i}$ Parameters } \\
\hline $\mathbf{t}$ & IT & AT & ARH \\
\hline 0.5 & 20.9 & 23.9 & 29.7 \\
\hline 1 & 21.2 & 23.4 & 30.6 \\
\hline 1.5 & 21.6 & 23.3 & 33.8 \\
\hline$\ldots$ & $\ldots$ & $\ldots$ & $\ldots$ \\
\hline 672 & 8.3 & 13.8 & 40.9 \\
\hline
\end{tabular}

Table 4. Calculation of complex maturity-strength relationship and the strength of boxes.

\begin{tabular}{|c|c|c|c|c|c|}
\hline \multirow{2}{*}{ Age, Days } & \multicolumn{3}{|c|}{ Maturity of $i$ Parameter } & \multirow{2}{*}{$\frac{\text { Complex Maturity, }{ }^{\circ} \mathrm{C} \cdot \text { Days }}{M_{c}}$} & \multirow{2}{*}{$\begin{array}{c}\text { Estimated Strength in Boxes, MPa } \\
C S\end{array}$} \\
\hline & $M_{I T}$ & $M_{A T}$ & $M_{A R H}$ & & \\
\hline 1 & 41.76 & 39.72 & 20.43 & 33.96 & 9.65 \\
\hline 2 & 73.31 & 107.37 & 36.76 & 69.03 & 14.44 \\
\hline 3 & 97.01 & 174.68 & 51.18 & 100.12 & 16.96 \\
\hline 4 & 119.46 & 245.08 & 64.25 & 130.96 & 18.77 \\
\hline 5 & 143.02 & 302.32 & 80.21 & 160.08 & 20.13 \\
\hline 6 & 169.33 & 345.37 & 98.36 & 187.64 & 21.20 \\
\hline 7 & 195.51 & 394.17 & 114.63 & 215.91 & 22.15 \\
\hline 8 & 220.34 & 444.27 & 130.40 & 243.75 & 22.97 \\
\hline 9 & 245.35 & 485.47 & 146.22 & 269.53 & 23.65 \\
\hline 10 & 268.13 & 530.46 & 158.87 & 294.22 & 24.24 \\
\hline 11 & 288.72 & 577.40 & 169.98 & 317.94 & 24.77 \\
\hline 12 & 308.81 & 629.17 & 180.77 & 342.52 & 25.27 \\
\hline 13 & 327.90 & 678.10 & 190.93 & 365.78 & 25.71 \\
\hline 14 & 346.39 & 724.01 & 200.85 & 387.97 & 26.11 \\
\hline 15 & 366.25 & 767.04 & 212.05 & 410.47 & 26.49 \\
\hline 16 & 385.93 & 818.35 & 222.76 & 434.74 & 26.88 \\
\hline 17 & 406.45 & 872.48 & 234.85 & 460.52 & 27.27 \\
\hline 18 & 428.39 & 922.70 & 248.34 & 486.41 & 27.64 \\
\hline 19 & 451.14 & 968.15 & 262.59 & 511.74 & 27.98 \\
\hline 20 & 474.30 & 1017.85 & 275.83 & 537.93 & 28.32 \\
\hline 21 & 489.89 & 1099.88 & 281.56 & 566.23 & 28.67 \\
\hline 22 & 504.88 & 1156.03 & 289.34 & 588.72 & 28.93 \\
\hline 23 & 522.73 & 1206.61 & 298.97 & 611.68 & 29.19 \\
\hline 24 & 539.95 & 1267.34 & 306.79 & 636.22 & 29.46 \\
\hline 25 & 556.23 & 1329.16 & 314.39 & 660.55 & 29.71 \\
\hline 26 & 572.76 & 1385.29 & 323.04 & 683.97 & 29.95 \\
\hline 27 & 590.62 & 1436.74 & 332.52 & 707.10 & 30.17 \\
\hline 28 & 608.83 & 1489.62 & 342.92 & 731.03 & 30.40 \\
\hline
\end{tabular}


To compare the estimated and actual compressive strengths, the strength of concrete in boxes was measured by the IPS-MG 4.01 sclerometer (Figure 4). It has a nonvolatile memory, a data transfer mode to a computer via a COM port and a function for entering individual calibration dependencies into the software device, set by the user. Measuring the strength of the concrete consists of applying a series of up to 15 blows to the controlled area of the product. The electronic unit, according to the parameters of the shock impulse coming from the sclerometer, evaluates the hardness and elastic properties of the test material, converts the impulse parameter into strength and calculates the corresponding class of concrete [22].

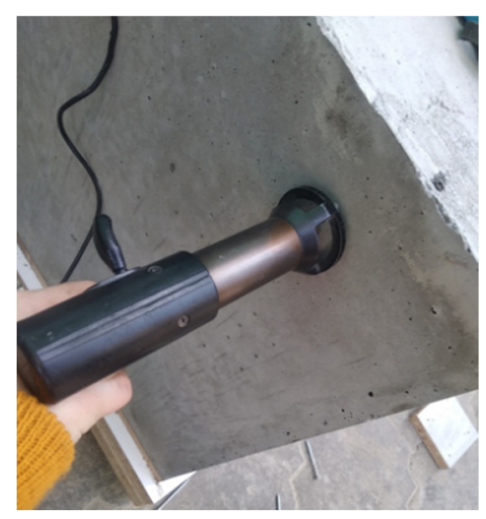

Figure 4. Determination of the strength of concrete in boxes obtained by the IPS-MG 4.01 sclerometer.

The proposed method provides more accuracy for pre-determining the complex maturity-strength relationship for each individual type of concrete. The relationship between strength and maturity is further used to determine the strength of the concrete structure while curing at the construction site, if temperature sensors were previously installed in these concrete structures. Moreover, the proposed method additionally takes accounts for the parameters of ambient temperature and relative humidity, and allows for determination of the strength of concrete at an early stage of concrete production. This, in turn, increases the possibility of reducing the waiting time for concrete curing and increasing the economic effect during construction.

\section{Results}

Internal temperature monitoring of the concrete samples in vertical cylinder molds and its average values are presented in Figure 5a for 28 days of curing.

Daily fluctuations in daytime and nighttime represent a spiky graph within certain limits; nevertheless, it is possible to trace the exothermic reaction that takes place during the curing of the concrete. The ambient temperature was positive during the concrete curing and varied between 3 and $25^{\circ} \mathrm{C}$ within $8-18{ }^{\circ} \mathrm{C}$ prevailing fluctuation. The ambient relative humidity generally showed a rather dry environment of $40-60 \%$, with two time jumps over four weeks of curing (Figure $5 b$ ).

The strength gain of concrete after the seventh day for specimens in cylindrical molds slows down a little, but then resumes a gradual growth, while the concrete in the boxes stabilizes and forms a gently sloping curve. The results for strength on the 1st, 3rd, 7th, 14th and 28th days are presented in Figure 6a. Since compression tests were only carried out on certain days, for the remaining days, the compressive strength was determined using the trend line shown in Figure 6a. The most fitting trend line and the corresponding formula, expressing the dependence of compressive strength on age for the concrete cylinders, is presented in natural logarithmic approximation. Further, Figure $6 \mathrm{~b}$ shows the maturitystrength relationship according to the [13] standard in accordance with Equation (1), based on only one parameter-internal temperature. 


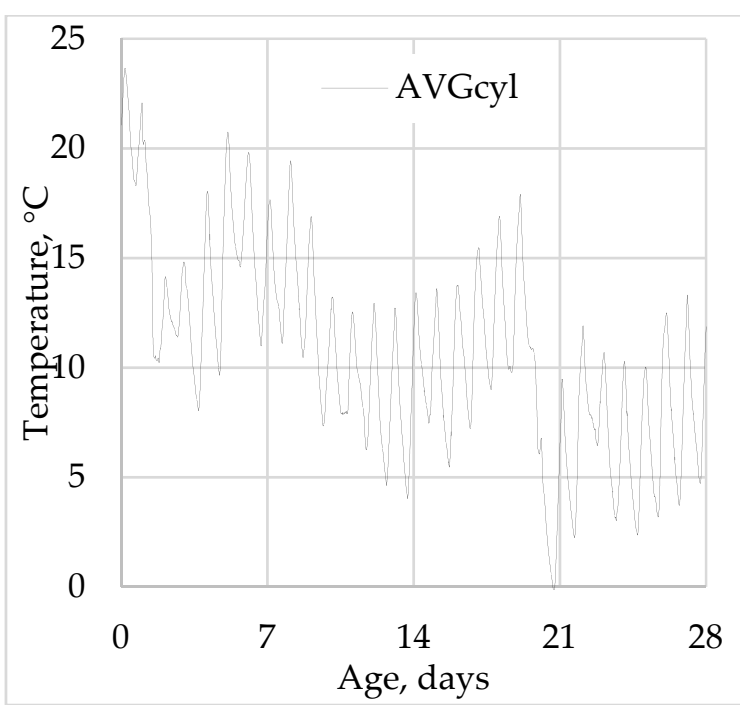

(a)

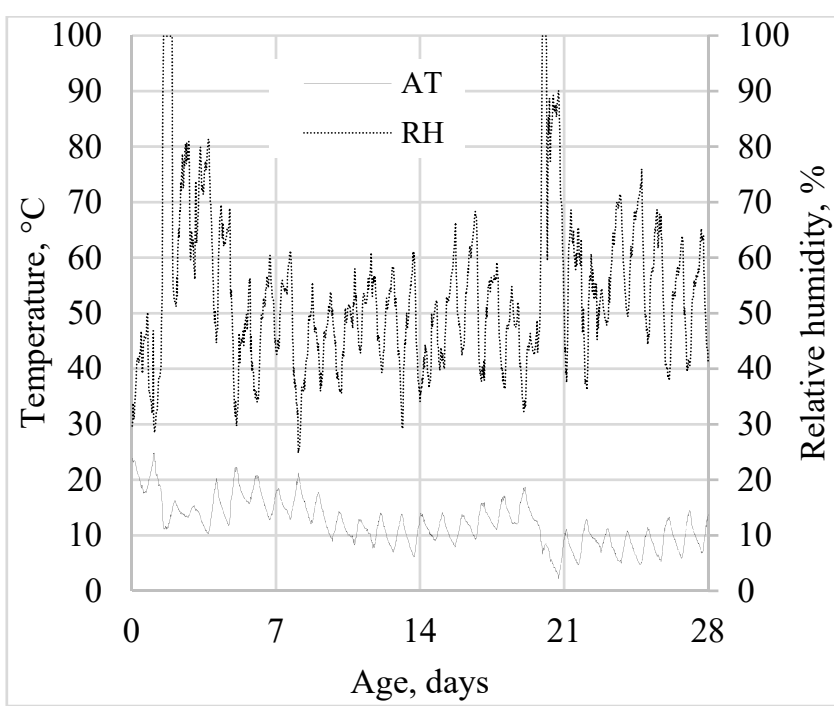

(b)

Figure 5. Temperature and humidity monitoring for concrete cylindrical samples over time: (a) Internal temperature fluctuation (average value); (b) Ambient temperature and ambient relative humidity.

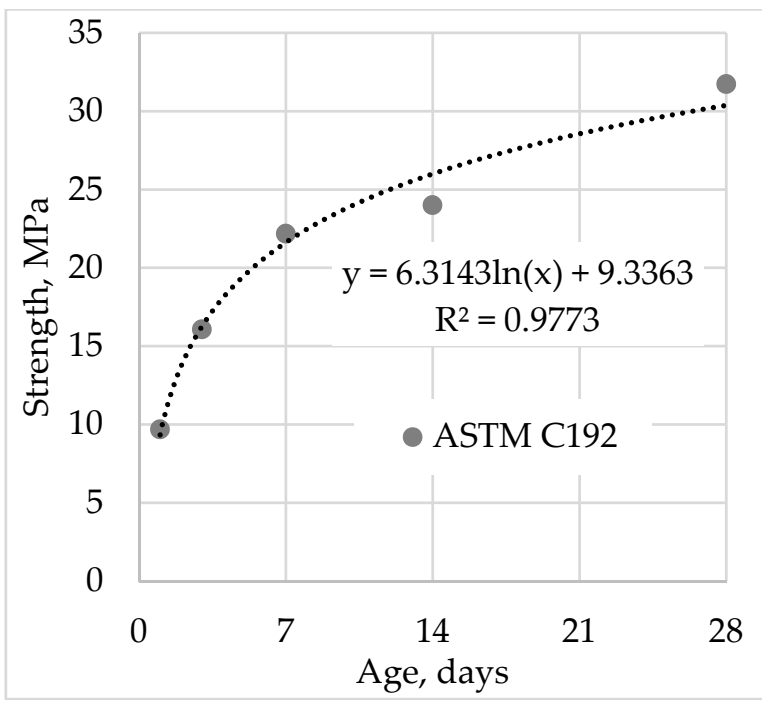

(a)

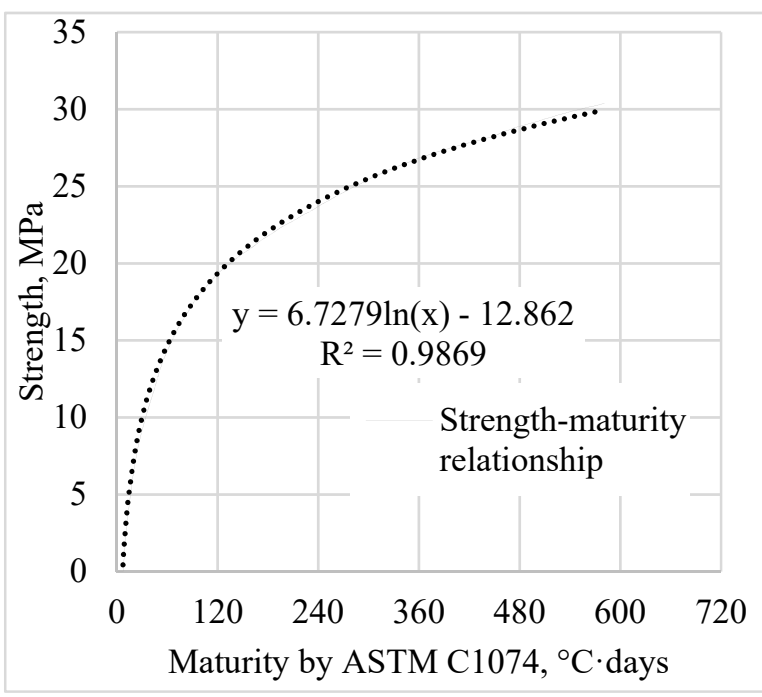

(b)

Figure 6. Concrete strength gained over time: (a) Compressive strength on the 1st, 3rd, 7th, 14th and 28th days; (b) Maturity-strength relationship according to [13].

In Figure 7, the complex maturity values calculated by Equations (2)-(7), and including the impact of IT, AT and ARH parameters, were presented in relation to the compressive strength cylinders, determined in Figure 6a. The corresponding trend line in natural logarithm approximation and a coefficient of determination $\mathrm{R}^{2}=0.9987$ confirm the high convergence. Knowledge of the relationship between the compressive strength and the complex maturity, determined for a given concrete mixture, enables estimation of the strength at any value of complex maturity on the site. For the concrete class B25, the necessary value to continue the construction is $22.4 \mathrm{MPa}$, which corresponds to $70 \%$ of standard strength of $32.0 \mathrm{MPa}$ on the 28th day.

The internal temperature history of concrete boxes chases a similar pattern of internal temperature in cylindrical samples, due to the simultaneous testing and identical ambient environment, although with less influence of daily fluctuation due to the higher volume of heat capacity of large concrete samples in the boxes (Figure 8). 


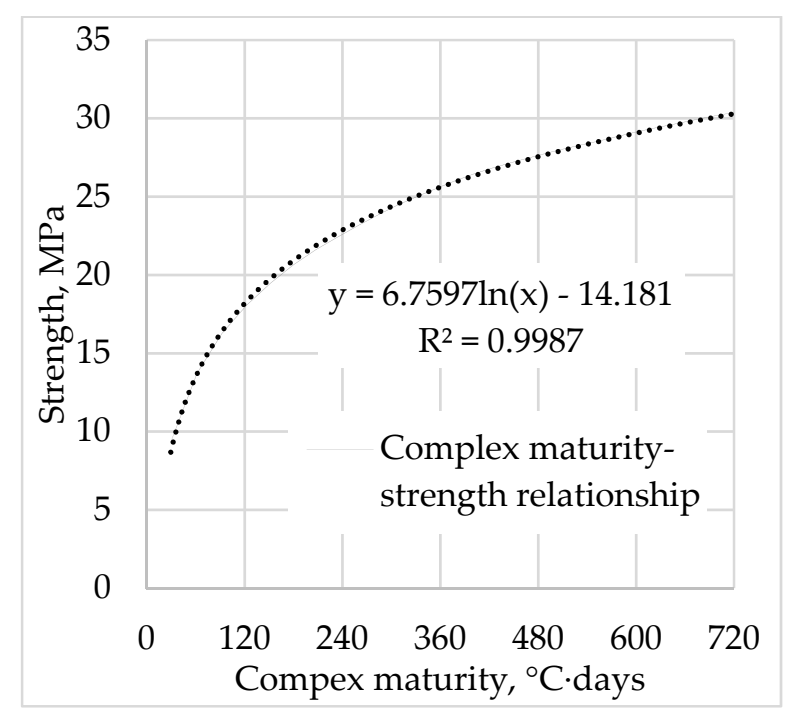

Figure 7. Complex maturity-strength relationship according to the proposed complex method.

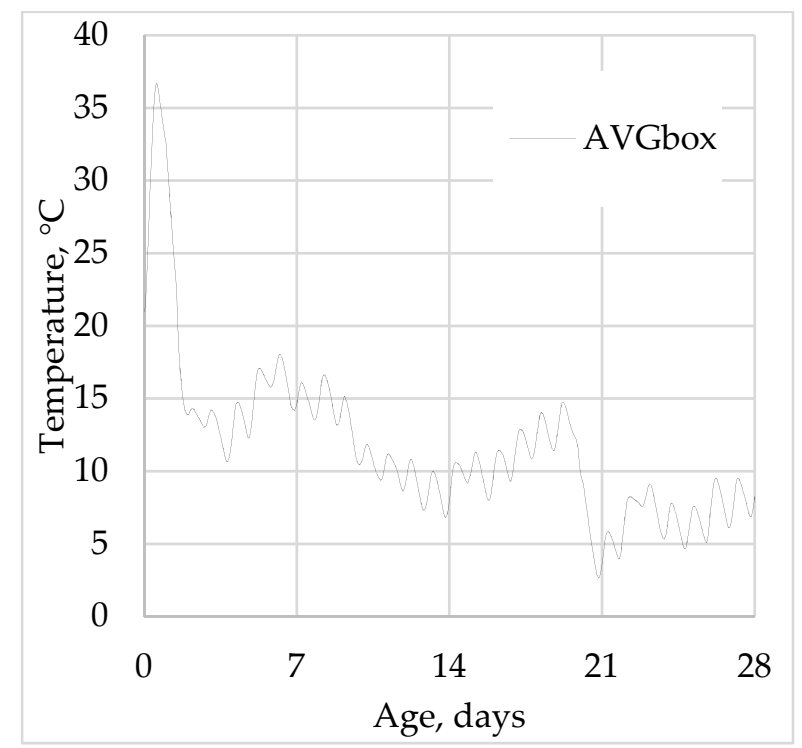

Figure 8. Internal temperature in the boxes (average value).

Using the maturity-strength relationships from Figures $6 \mathrm{~b}$ and 7 , the internal temperature history from Figure 8, ambient temperature and relative humidity history from Figure 5b, and Equations (1)-(4), the current strength values in boxes were estimated for the Nurse-Saul and the proposed methods. The maturity values at each period were calculated using the average values of internal temperature in boxes.

Figure 9 shows the values of concrete strength measured by non-destructive testing with IPS-MG 4.01 sclerometer in both boxes and their average.

The results obtained by various strength methods on the 1st, 3rd, 7th, 14th and 28th days of concrete curing are presented in Table 5 , where strength in boxes, representing the construction on the site was measured by the IPS-MG 4.01 sclerometer, as well as estimated by [13] and the proposed method of complex maturity. 


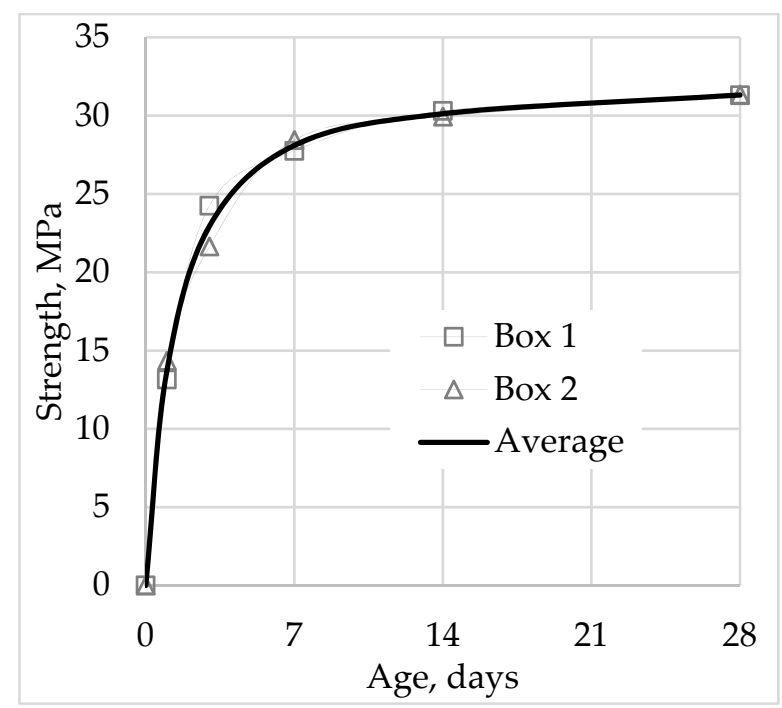

Figure 9. Strength of concrete in boxes measured by IPS-MG 4.01 sclerometer.

Table 5. Results of strength tests determined by various methods.

\begin{tabular}{|c|c|c|c|c|c|c|c|}
\hline \multirow{3}{*}{ Age, Day } & \multicolumn{5}{|c|}{ Results of Strength Tests, MPa } & \multicolumn{2}{|c|}{ Estimated Strength, MPa } \\
\hline & \multirow{2}{*}{$\begin{array}{c}\text { ASTM C192 } \\
\begin{array}{c}\text { Cylinders } \\
(\$ 15 \times 15 \mathrm{~cm})\end{array}\end{array}$} & \multirow{2}{*}{$\begin{array}{c}\text { GOST } 10180 \\
\text { Cubes } \\
(10 \times 10 \times 10 \mathrm{~cm})\end{array}$} & \multicolumn{3}{|c|}{ GOST 22690} & \multirow{2}{*}{$\begin{array}{l}\text { ASTM } \\
\text { C1074 }\end{array}$} & \multirow{2}{*}{ Proposed } \\
\hline & & & $\begin{array}{c}\text { Box } 1 \\
(50 \times 50 \times 50 \mathrm{~cm})\end{array}$ & $\begin{array}{c}\text { Box } 2 \\
(50 \times 50 \times 50 \mathrm{~cm})\end{array}$ & $\begin{array}{l}\text { Average in } \\
\text { Boxes }\end{array}$ & & \\
\hline 1 & 9.67 & 12.2 & 13.15 & 14.35 & 13.75 & 12.25 & 9.65 \\
\hline 3 & 16.06 & 20.45 & 24.25 & 21.65 & 22.95 & 17.92 & 16.96 \\
\hline 7 & 22.17 & 24.25 & 27.75 & 28.45 & 28.1 & 22.63 & 22.15 \\
\hline 14 & 23.99 & 26.75 & 30.3 & 29.95 & 30.125 & 26.48 & 26.11 \\
\hline 28 & 31.72 & 34.2 & 31.3 & 31.35 & 31.325 & 30.27 & 30.40 \\
\hline
\end{tabular}

\section{Discussion}

Combining all the obtained results with the general parameters in Figure 10, the following test methods were compared in order to determine the strength gain over time:

- $\quad$ The compression testing of the cubes with an edge size of $10 \mathrm{~cm}$ by [14] represented by square markers;

- $\quad$ The non-destructive testing of the boxes using the IPS-MG 4.01 sclerometer [22] represented by triangle markers;

- $\quad$ The maturity-strength method by [13] represented by a dashed line;

- The proposed complex maturity method, based on [13] and modified, accounting for additional influencing parameters, such as the ambient temperature and relative humidity represented by the circle markers on the graph.

Since all the standards used in this work, or rather, the results obtained by assessing the strength of concrete, are compared with the results from an assessment of the strength of cubic samples, Figure 11 shows the calibration dependence of the above methods in relation to the direct method of the compression testing of cubic samples along the $x$-axis. The corresponding trend lines were supported by the coefficients of determination for each method.

The results for the coefficients of determination characterize the degree of convergence or reliability of the presented methods, in comparison with those from the compression testing of cubic samples. Thereby, the highest coefficient of determination $R^{2}=0.976$ was revealed for the proposed method of complex maturity. The lowest $R^{2}=0.8929$ was revealed for [22], representing the non-destructive measurement method of strength in 
boxes by sclerometer. The Nurse-Saul maturity method [13] for estimating the current strength of concrete, which considers only internal temperature, was found to be reliable enough, although it is worth noting that the ambient parameters are also important for the concrete curing process.

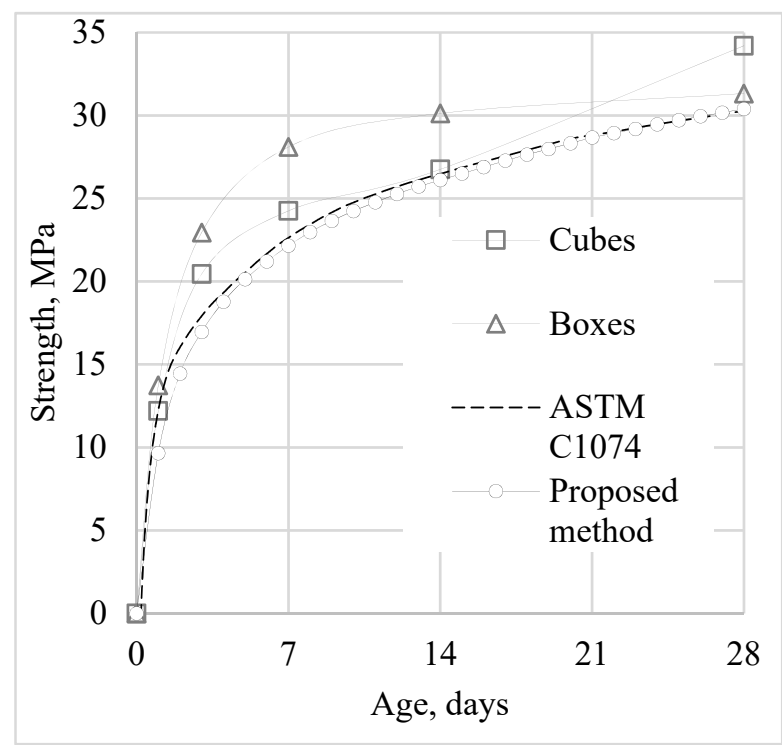

Figure 10. Summary results of concrete strength determined by various methods.

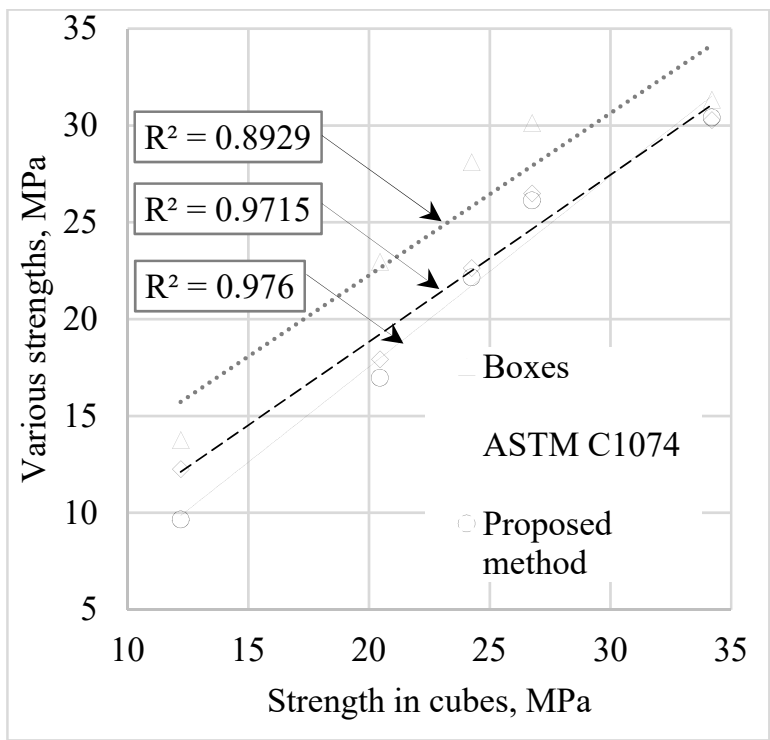

Figure 11. Calibration dependence of the above methods in relation to the compressive strength of cubic samples.

\section{Conclusions}

Summarizing the results of the experimental work on the development of a method for assessing the strength of concrete by complex maturity, the following conclusions have been made:

1. The laboratory tests for measuring the concrete strength by compression method and non-destructive sclerometer method were performed on concrete samples according to ASTM C109, GOST 10180 and GOST 22690. The estimated current strength values of concrete were obtained by ASTM C1074 (Nurse-Saul) and the proposed complex maturity methods. 
2. Assessment of concrete strength by the proposed method was based on ASTM C1074 and developed by taking the influence of ambient temperature and relative humidity into account when calculating the complex maturity.

3. The estimated and measured by various methods strength were analyzed on the $1 \mathrm{st}, 3 \mathrm{rd}, 7 \mathrm{th}, 14 \mathrm{th}$ and $28 \mathrm{th}$ days of concrete curing and compared with the strength obtained from the results of compression tests of cubes with an edge size of $10 \mathrm{~cm}$, according to GOST 10180.

4. According to the calibration dependence of the existing and proposed methods in relation to the strength gained in cubic samples, the highest coefficient of determination $R^{2}=0.976$ was revealed for the proposed method of strength estimation by complex maturity, which indicates the reliability of the latter.

Determination of the complex maturity of concrete makes it possible to assess the current state of its strength and, above all, to reduce the waiting time for concrete maturation and increase the economic effect during construction. The proposed method accounts for the influence of internal and ambient temperature and ambient relative humidity on the strength gain of concrete and provides with the most reliable data at an early stage of concrete curing.

Author Contributions: Conceptualization, Y.U.; methodology, A.S.; software, S.Z.; validation, A.A. (Aliya Aldungarova); formal analysis, A.S.; investigation, Y.U. and S.Z.; writing-original draft preparation, A.S. and Y.U.; writing - review and editing, A.A. (Aleksej Aniskin); visualization, S.Z.; supervision, A.T.; project administration, A.T.; funding acquisition, Y.U. All authors have read and agreed to the published version of the manuscript.

Funding: This research was funded by the Science Committee of the Ministry of Education and Science of the Republic of Kazakhstan (Grant No. AP08052033).

Institutional Review Board Statement: Not applicable.

Informed Consent Statement: Not applicable.

Data Availability Statement: The data presented in this study are available on request from the first author. doi:10.1061/40558(2001)17.

Conflicts of Interest: The authors declare no conflict of interest.

\section{References}

1. Saul, A.G.A. Principles underlying the steam curing of concrete at atmospheric pressure. Mag. Concr. Res. 1951, 2, 127-140. [CrossRef]

2. Hansen, P.F.; Pedersen, E.J. Maturity computer for controlled curing and hardening of concrete. Nord. Betong 1977, 1, $19-34$.

3. CHENGJU, G. Maturity of concrete-Method for predicting early-stage strength. ACI Mater. J. 1989, 86, 341-353.

4. Carino, N.J.; Lew, H.S. The Maturity Method: From Theory to Application. Struct. Congr. Expo. Am. Soc. Civ. Eng. 2001. [CrossRef]

5. Plowman, J.M. Maturity and the strength of concrete. Mag. Concr. Res. 1956, 8, 13-22. [CrossRef]

6. Tekle, B.H.; Al-Deen, S.; Anwar-Us-Saadat, M.; Willans, N.; Zhang, Y.; Lee, C.K. Use of maturity method to estimate early age compressive strength of slab in cold weather. Struct. Concr. 2021, 1-15. [CrossRef]

7. Ustabaş, I.; Deşik, F. Transition coefficients between compressive strengths of samples with different shape and size in mass concrete and use of weight maturity method in dam construction. Struct. Concr. 2021, 22, E696-E709. [CrossRef]

8. Yikici, T.A.; Chen, H.-L. (Roger) Use of maturity method to estimate compressive strength of mass concrete. Constr. Build. Mater. 2015, 95, 802-812. [CrossRef]

9. Nandhini, K.; Karthikeyan, J. The early-age prediction of concrete strength using maturity models: A review. J. Build. Pathol. Rehabil. 2021, 6, 7. [CrossRef]

10. Nixon, J.M. Evaluation of Maturity Method to Estimate Concrete Strength in Field Applications; Auburn University: Auburn, Alabama, 2006.

11. Sun, B.; Noguchi, T.; Cai, G.; Chen, Q. Prediction of early compressive strength of mortars at different curing temperature and relative humidity by a modified maturity method. Struct. Concr. 2021, 22, E732-E744. [CrossRef]

12. Barroca, N.; Borges, L.M.; Velez, F.J.; Monteiro, F.; Górski, M.; Castro-Gomes, J. Wireless sensor networks for temperature and humidity monitoring within concrete structures. Constr. Build. Mater. 2013, 40, 1156-1166. [CrossRef]

13. ASTM C1074. Standard Practice for Estimating Concrete Strength by the Maturity Method; American Society for Testing and Materials: West Conshohocken, PA, USA, 2019. 
14. GOST 10180. Concretes. Methods for Strength Determination Using Reference Specimens; Interstate standardization organization: Moscow, Russia, 2012.

15. NEN 5970. Determination of Strength of Fresh Concrete with the Method of Weighted Maturity; Delft, Netherlands, 2001. Available online: https:/ / standards.globalspec.com/std/10294720/nen-5970 (accessed on 1 September 2001).

16. ST-NP SRO SSK-04. Temperature and Strength Control of Concrete during the Construction of Monolithic Structures in Winter; Chelyabinsk, Russia, 2013. Available online: https:/ / www.russiangost.com/p-169830-st-np-sro-ssk-04-2013.aspx (accessed on 18 July 2013).

17. BS EN 13791. Assessment of In-Situ Compressive Strength in Structures and Precast Concrete Components; London, UK. Available online: https: / shop.bsigroup.com/products / assessment-of-in-situ-compressive-strength-in-structures-and-precast-concretecomponents?pid=000000000030349923 (accessed on 31 January 2020).

18. Brooks, A.G.; Schindler, A.K.; Barnes, R.W. Maturity Method Evaluated for Various Cementitious Materials. J. Mater. Civ. Eng. 2007, 19, 1017-1025. [CrossRef]

19. Soutsos, M.; Hatzitheodorou, A.; Kwasny, J.; Kanavaris, F. Effect of in situ temperature on the early age strength development of concretes with supplementary cementitious materials. Constr. Build. Mater. 2016, 103, 105-116. [CrossRef]

20. Tada, S.; Watanabe, K. A Dynamic Method Determining Equilibrium Moisture Content of Porous Materials. In Proceedings of the 4th International Symposium on Humidity and Moisture, Taipei, Taiwan, 16-19 September 2002; pp. 318-324.

21. ASTM C192/C192M. Standard Practice for Making and Curing Concrete Test Specimens in the Laboratory; American Society for Testing and Materials: West Conshohocken, PA, USA, 2019. [CrossRef]

22. GOST 22690. Concretes. Determination of Strength by Mechanical Methods of Nondestructive Testing; Moscow, Russia, 2015. Available online: https:/ / fresh-deko.ru/en/fruit-trees/ispytanie-betona-gost-22690-opredelenie-prochnosti-mehanicheskimi.html (accessed on 25 September 2015).

23. Utepov, Y.B.; Khudaibergenov, O.A.; Kabdush, Y.B.; Kazkeev, A.B. Prototyping an embedded wireless sensor for monitoring reinforced concrete structures. Comput. Concr. 2019, 24, 95-102. [CrossRef] 